\title{
A Preliminary Investigation of Parent-Progeny Olfactory Recognition and Parental Investment
}

\author{
Judith Semon Dubas • Marianne Heijkoop • \\ Marcel A. G. van Aken
}

Published online: 31 January 2009

(C) The Author(s) 2009. This article is published with open access at Springerlink.com

\begin{abstract}
The role of olfaction in kin recognition and parental investment is documented in many mammalian/vertebrate species. Research on humans, however, has only focused on whether parents are able to recognize their children by smell, not whether humans use these cues for investment decisions. Here we show that fathers exhibit more affection and attachment and fewer ignoring behaviors toward children whose smell they can identify than toward those whose smell they cannot recognize. Thus, olfaction might serve as a means for males to determine their genetic relatedness to purported offspring. We also demonstrate that mothers' olfactory recognition and hedonistic ratings are linked with the use of physical punishment. Mothers report using more punishment with children whose odor they cannot recognize and less with children whose odor they rated as more pleasant. These results provide the first preliminary evidence in humans that olfactory cues may guide parents in the allocation of care.
\end{abstract}

Keywords Parental investment $\cdot$ Kin recognition $\cdot$ Olfaction

Members of mammalian and vertebrate species commonly use olfactory signatures (phenotypes) to distinguish between individual members and to denote various subgroups, including the recognition of kin versus non-kin (Porter 1998; Reynolds and Sheldon 2003). Kin selection theory (Hamilton 1964) predicts that organisms will preferentially aid more closely related kin over more distantly related kin or non-kin. The role of olfaction in kin recognition and parental investment is documented in many mammalian/vertebrate species (Mateo 2002; Yamazaki et al. 2000). Research on humans, however, has only focused on whether parents are able to recognize their children (mostly infants) by smell (Kaitz et al. 1987; Porter and Moore 1981; Weisfeld et al. 2003), not whether and how humans use these cues for investment decisions. Instead, a growing line of research focuses on whether parents use facial resemblance

J. S. Dubas $(\bowtie) \cdot$ M. Heijkoop • M. A. G. van Aken

Developmental Psychology, Utrecht University, P. O. Box 80140, 3508 TC Utrecht, The Netherlands e-mail: J.J.S.Dubas@uu.nl 
cues (as an index for genetic relatedness) for parental investment decisions (e.g., Apicella and Marlowe 2004; Platek et al. 2004a). In the current study we focus on olfaction as a means of kin recognition and study its link to parental investment since olfaction may have had certain advantages over other sensory cues.

Porter (1998) outlines several advantages of olfaction as a mechanism of kin recognition. First, in contrast to visual cues, odor perception is not dependent on the presence of ambient light and is therefore effective throughout the day-night cycle. Second, unlike auditory cues, odors are accessible regardless of the sleep/awake state of the source. Third, olfactory signals can remain active even when the source is absent because they are excreted onto other objects. Finally, olfactory cues remain relatively stable throughout the life course, thereby providing long-term labels of identity that can be reliably identified regardless of the source's age. This last point is particularly relevant given that there is considerable change in facial and physical appearance from infancy through adolescence (Pagel 1997; Tanner 1978).

The term odortype refers to the genetically programmed body odors that uniquely distinguish individuals (Yamazaki et al. 1999). Genes of the major histocompatibility complex (MHC) confer this personal olfactory identity (Potts et al. 1994; Yamazaki et al. 2000). Heterozygosity in the MHC decreases susceptibility to infectious disease, and it seems likely that selection pressures would lead to the evolution of reproductive mechanisms that allowed parents to preferentially produce diseaseresistant, MHC-heterozygous offspring (Eggert et al. 1998; Yamazaki et al. 1999, 2000). Humans have the ability to discriminate MHC-mediated odor types and exhibit MHC-disassortative mating patterns (Gilbert et al. 1986; Jacob et al. 2002). In addition, mothers prefer the (axillary) smell of a strange child to that of their own child of either sex, and fathers prefer the smell of a strange female child to that of their daughter (Weisfeld et al. 2003). Thus, in addition to increasing fitness and the avoidance of inbreeding, we hypothesize that the ability to discriminate MHCmediated odortypes may also be involved in the allocation of parenting effort. That is, we propose that these odor signatures may be used as a means of identifying kin for the purpose of discriminative parental solicitude.

While most mothers and many fathers are able to recognize their children's odortypes, considerable individual differences are reported. For mothers, this accuracy has ranged from $66 \%$ to $100 \%$ (Kaitz et al. 1987; Porter et al. 1983a, 1983b; Porter and Moore 1981; Russell et al. 1983; Weisfeld et al. 2003), whereas for fathers, a much wider range of precision has been exhibited, ranging from $37 \%$ to 94\% (Porter et al. 1986; Russell et al. 1983; Weisfeld et al. 2003). While some of this variability may be due to differences in methodologies, a wide range of individual differences in olfactory skills has also been found (e.g., Mackay-Sim et al. 2004). The study reported herein was designed to examine whether human kin recognition of pre-pubertal offspring plays a role in the degree of investment parents make in their children. If olfactory kin recognition serves to promote parental investment, parental olfactory recognition of a child will be positively associated with parental investment, and such a relation should be found for both mothers and fathers. If olfactory recognition increases certainty of biological parenthood particularly for males, then the relation between parental olfactory recognition and parental investment should be moderated by the gender of the parent. That is, the size of the effect is expected to be larger for men than for women and/or more 
investment parameters would be affected. We focused on five measurements of investment: parental self-report on the emotional closeness and amount of time spent with the child, and the use of physical punishment (as a form of negative investment), and observed measures of parental affection toward and ignoring of the child.

Because a number of factors may influence adults' olfactory skills, we investigated four additional variables. Specifically, we focused on parental smoking status and whether anyone smoked in the house. Smokers have been found to have a higher olfaction threshold than nonsmokers (Good et al. 2003), and the ambient odor of smoke may permeate children's clothing, facilitating odor recognition. We also examined whether mothers' menstrual cycle phase and use of oral contraception were possible confounds since the highest degree of olfactory sensitivity coincides with the ovulatory phase (Pause et al. 1996), and women who use oral contraception lose this peak sensitivity (Caruso et al. 2001).

In addition to olfactory recognition, we also investigated the degree to which parents found the odor of their children attractive. We compared parents' hedonistic ratings of their children's odors to that of the age- and sex-matched control and whether this varied as a function of parents' being able to discriminate between their own child and the control child. In this way, we could assess whether olfactory discrimination is linked to both odor preferences (as a proxy for inbreeding avoidance) and parental investment. If odors serve a role in inbreeding avoidance, parents should rate their own children's odors as less pleasant than those of strangers' children. At the same time, however, pleasantness of an individual's odor may also serve as a signal of lack of disease (Penn and Potts 1998). Parents may use pleasantness ratings of their children's odors in allocating care. Thus, a final goal of this investigation was to examine whether the pleasantness of a child's odor is related to the degree of parental investment.

\section{Method}

\section{Sample}

Families were recruited via their fourth- or fifth-grade child attending elementary schools in the Netherlands. Children were given a brief demonstration about olfaction and asked to take letters describing the study and consent forms home to their parents. Parent(s), the target child (8-9 years old), and, if possible, one sibling (4-11 years old) were invited to participate. In total, 66 mothers, 39 fathers, and 99 children, representing 68 different families, agreed to participate and completed the olfaction study. In 33 families both parents participated. All children were the purported biological offspring of the parents who participated in this study; $88.5 \%$ of the fathers and $75 \%$ of the mothers were currently married or cohabiting (cohabiting in the Netherlands is common and virtually equivalent to being married). The sample primarily represents Dutch middle- and upper-middleclass families. Among fathers, 24\% had completed a lower educational training, $28 \%$ a higher technical degree, and $56 \%$ a university degree. For mothers, $19 \%$ had completed a lower educational training, 35\% a higher technical degree, and 
$46 \%$ a university degree. Mean ages of participants were 44 years for fathers, 41 years for mothers, and 9 years for children.

\section{Procedure}

All families were visited twice in their homes by two developmental psychology master's students. During the first visit T-shirts were distributed and the smell task was described. Parents were told that they would be tested on their ability to recognize their children at the next visit. Parents also completed questionnaires that assessed individual characteristics of parents and children and parental investment. Observations concerning how the parents interacted with their child(ren) were made during this first visit. The second visit was conducted 3 days later and included the odor rating and recognition task. The first visit lasted, on average, $90 \mathrm{~min}$ and the second visit lasted about $30 \mathrm{~min}$.

\section{Measures}

Parental Investment We used three measures of parental investment reported by the parents. Emotional closeness was measured using the mean of eight items from existing Dutch parenting measures; four items tapped how attached the parent feels to the child (de Brock et al. 1992), and four items tapped how often the parent expresses affection toward the child (Gerris et al. 1993). The four items from the attachment scale are: "I feel that I have a close bond with this child," "I worry that this child does not love really love me" (reverse coded), "My feelings for this child are less warm and close than I expected" (reverse coded), "Sometimes I think that I do not have such a close bond with my child" (reverse coded). The four items from the affection scale are: "I often let my child know that I love him/her," "I hug this child often," "I often compliment this child," and "Sometimes I say to my child, 'You are my little angel,' or the equivalent." Cronbach's alphas were satisfactory (father-child $1=0.87$, father-child $2=0.74$, mother-child $1=0.88$, mother-child $2=0.90$ ). Parents also reported on their use of physical punishment on one item: "I regularly give this child a slap." Parents rated each of the two quality of the relation items and the physical punishment item on a scale ranging from 1 (not at all true) to 7 (very true). The amount of time parents spend actively involved with the child each week was assessed by having parents estimate the amount of time engaged in six activities with the child on a daily basis (TV viewing, eating, assisting with homework, playing/reading, household tasks, and going out) (Dubas and Gerris 2002).

We also observed parent-child interactions during the first home visit. Each trained observer independently assessed parental behaviors immediately after the visit and did not discuss ratings with the other observer. Affection was assessed as the degree to which each parent initiated and expressed warmth in their interactions with the child, such as using loving words and/or giving the child a hug. Ignoring was assessed as the degree to which each parent did not pay attention to or react to expressions or behaviors of the child that normally would get a response from the parent. These ratings were assessed on a four-point scale: $1=$ absent, $2=$ small degree present, $3=$ an average amount, and $4=$ high degree present. Interrater agreement was reasonable considering these observations were made as general 
impressions during the visit and not based on specific tasks that both observers deliberately watched. Interrater agreement as assessed by Pearson's correlation coefficient were fathers' affection $r=0.48, p<0.001$ and ignoring $r=0.61, p<0.001$; mothers' affection $r=0.42, p<0.001$ and ignoring $r=0.35, p<0.001$. Mean affection and ignoring scores across the two observers were used in the analyses. All parenting scores were standardized-i.e., converted to $z$ scores with a mean of 0 and a standard deviation of 1 .

Olfactory task A procedure similar to that of Porter and Moore (1981) was used. Each child received a new, 100\% cotton, long-sleeved T-shirt that was prewashed using odorless laundry detergent and fabric softener. Parents were instructed to have their children wear the shirt to bed for three consecutive nights and avoid using scented soaps and perfumes or having pets in the child's bedroom at night. The children were given unscented soap for use during the study. Each shirt was kept in its own sealed plastic bag during the day.

After three nights of wear, the shirts were folded and rolled in such a manner that the axillary seams of the shirt were exposed. The shirt was then placed in a new plastic bag which was then placed in a plastic beaker $(25 \mathrm{~cm} \mathrm{H} \times 10 \mathrm{~cm} \mathrm{D})$. Mothers and fathers were tested individually and were blindfolded during the hedonistic rating and the odor identification task. For the hedonistic rating task, parents were presented with a plastic beaker that held either their own child's T-shirt or a T-shirt worn by an age- and sex-matched control child and were asked to smell the T-shirt and rate the pleasantness of the odor on a five-point scale consisting of $1=$ very unpleasant, 2 = unpleasant, $3=$ neutral, $4=$ pleasant, and $5=$ very pleasant. Order of presentation of the shirts was random. For the olfaction task, parents were presented with two identical tall plastic beakers: one containing their own child's T-shirt and one containing a T-shirt worn by an age- and sex-matched control child. Parents were asked to identify which container held their child's T-shirt. There was no time limit. Three pairwise comparisons were conducted per child; that is, the parents were asked to choose which container (child vs. control) held their child's T-shirt three times. All handling of T-shirts for the olfaction task was conducted with disposable vinyl gloves to obviate odor contamination. If parents smoked, they were asked not to do so in and around the child's bedroom. On the day of the olfaction task they were asked not to smoke for at least one hour prior to the test. Total correct per child was used as the olfactory recognition score.

Possible Confounding Factors Parents reported on their current smoking status. Almost one third of the parents currently smoked $(31.4 \%$ fathers and $28.3 \%$ mothers). We also asked whether anyone else smoked in the home. Households were then classified as smoke-free $(63 \%)$ or non-smoke-free $(37 \%)$. Mothers reported on their reproductive history, including whether they were currently on oral contraception (30\% yes) and their current menstrual status. Women indicated whether they had regular menstrual cycles, the length of their cycles in days, and the first day of their most recent menstrual cycle. Women with complete information on these questions (and who were not pregnant, menopausal, or oral contraception users) were classified as ovulatory $(41 \%)$ if within 3 days of their midcycle or otherwise non-ovulatory (59\%). 


\section{Results}

\section{Gender Differences in Olfaction}

Mothers and fathers did not significantly differ in their ability to identify their children's odors (mothers' mean accuracy $=2.23$, fathers' mean accuracy $=1.95$; difference $=0.37 ; 95 \%$ CI $\left.-0.088<0<0.818, t_{116}=1.58, p=0.12\right)$. Children were classified as recognized or not based on the parent's olfactory recognition score. Specifically, if parents correctly identified a child's T-shirt at least two out of three times the respective child was classified as recognized; if not, the respective child was labeled as non-recognized. ${ }^{1}$ A slightly higher percentage of mothers accurately recognized their children $(79.4 \%)$ than did fathers $(67.7 \%)$, although this difference was not significant $\left(\chi^{2}=2.801, p=0.094\right)$.

\section{Olfactory Recognition and Parental Investment}

We used analysis of covariance to examine whether mothers and fathers invested more in children they were able to identify than in children they were not able to identify. Age of the child was a covariate in all analyses since parenting behavior can differ based on a child's developmental stage; moreover this control also serves a proxy for length of coresidence. Fathers' olfactory recognition was related to their parental investment, but no effects were found for mothers. Specifically, fathers reported more affection and attachment $\left(F_{1,55}=6.32, p=0.015\right)$ and exhibited less ignoring behaviors $\left(F_{1,54}=4.74, p=0.034\right)$ toward their children whose odor they identified than toward children whose odors they could not identify (Fig. 1). No differences in parental time investment or observed affection as a function of olfactory recognition were found. Age was not a significant covariate.

Additional analyses revealed that the link between kin recognition and parental investment was not confounded by parental smoking status, maternal oral contraception use, maternal menstrual cycle phase, or the amount of time parents spend with their children. Moreover, when our analyses were limited to just the target child (roughly 8- to 10-year-olds), to avoid any shared method variance because of the nested design, the main findings were similar.

We did find, however, that fathers' (but not mothers') recognition was associated with whether or not the home was smoke-free $\left(F_{1,50}=5.36, p=0.025\right)$. Specifically, fathers who lived in a smoke-free environment were poorer at recognizing their children's odors (mean=1.72) than fathers who lived in a non-smoke-free home $($ mean $=2.45)$. Because of this effect we then repeated the ANOVA described above

\footnotetext{
${ }^{1}$ We examined the link between olfactory recognition and parental investment using both dichotomous scores (recognized/non-recognized) in ANOVA and using the accuracy scores as a continuous variable in the correlations and regressions. Given that we only had three trials per child it was not possible to classify children as reliably identified using criteria from the binomial distribution, since the probabilities for getting $0,1,2$, or 3 trials correct, respectively, are $0.125,0.375,0.375$, and 0.125 . We ran additional analyses comparing parents who recognized their child's T-shirt correctly on all three trials with parents who either never recognized their child's T-shirt or identified their child's T-shirt on only one of three trials. Results from those analyses were identical to the results reported here.
} 
Fig. 1 a Parental affection/ attachment (mean $z$-score \pm standard error) to child as a function of fathers' and mothers' ability to recognize the child's odor. b Parental ignoring behavior towards child as a function of fathers' and mothers' ability to recognize the child's odor. All parenting behaviors have been standardized ( $z$-score) to $M=0$ and $\mathrm{SD}=1$; group differences are interpretable in SD unit differences (d)
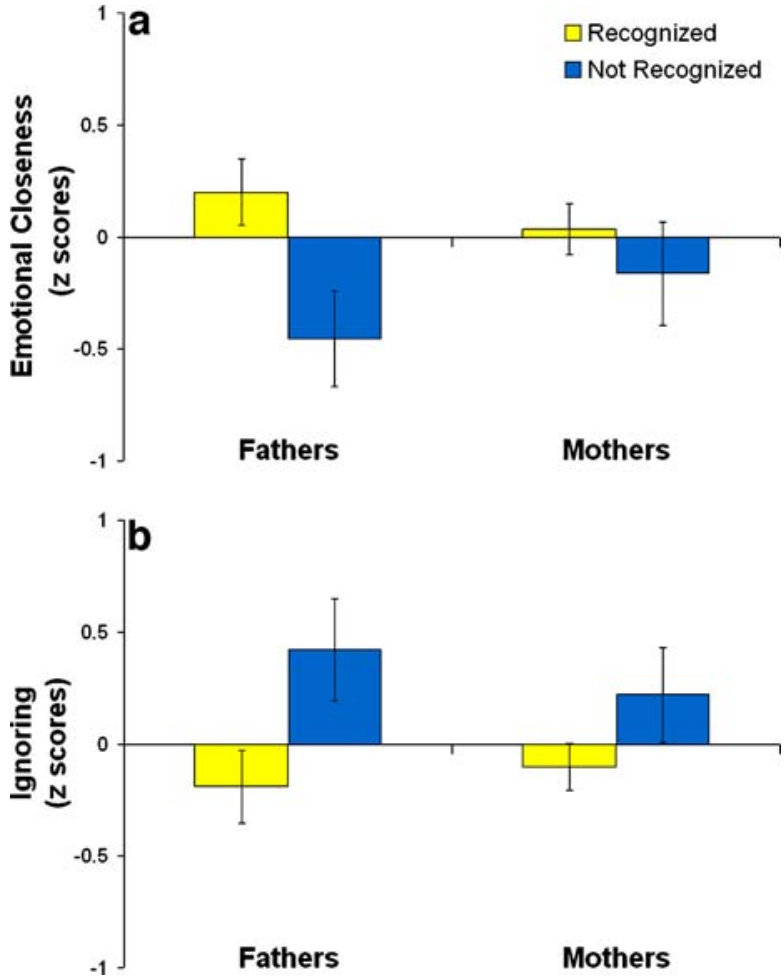

for only those parents who lived in a smoke-free home. The results for fathers were essentially the same as those reported above. Specifically, fathers reported more affection and attachment $\left(F_{1,29}=7.94, p=0.009\right)$ and exhibited fewer ignoring behaviors $\left(F_{1,29}=4.47, p=0.044\right)$ toward their children whose odor they identified than toward their children whose odors they were not able to identify. In addition, there was a trend for fathers to use less physical punishment with children whose smell they could identify $\left(F_{1,29}=3.23, p=0.083\right)$, relative to those they could not identify.

\section{Olfactory Recognition and Hedonistic Ratings of Own Child Versus Control}

Analysis of covariance was also used to examine whether mothers and fathers rated the hedonistic value of the odors differently as a function of child type (own child/ control), child sex, and recognition status. Age of the child was a covariate in all analyses. Fathers rated the smell of the control child as more pleasant than that of their own child $\left(F_{1,55}=5.15, p=0.027\right.$; own child mean $=3.05, \mathrm{SE}=0.10$; control child mean=3.15, $\mathrm{SE}=0.14$ ). There were no main effects of recognition on hedonistic ratings, nor did recognition interact with the other factors. For mothers, the odor of males was rated as more pleasant than the odor of females $\left(F_{1,93}=3.93\right.$, $p=0.01$; mean for males $=3.39, \mathrm{SE}=0.09$; mean for females $=3.03, \mathrm{SE}=0.09$ ). No other effects were significant. We also conducted these same analyses with the additional factor of whether or not the home atmosphere was smoke-free. No main 
effects or interactions of home atmosphere (smoke-free or not) on hedonistic ratings were found.

Hedonistic Ratings of Own Child and Parental Investment

The Pearson correlations between parents' pleasantness ratings of their children's odors and the five markers of parental investment are presented in Table 1. For fathers, no significant associations were found. For mothers, the only significant finding was the positive correlation between hedonistic ratings and use of physical punishment. That is, mothers who rated their children's odor as more pleasant reported using more physical punishment.

Odor Recognition and Hedonistic Ratings as Simultaneous Predictors of Parental Investment

We used multiple regression analysis to examine the simultaneous associations between olfactory recognition and hedonistic ratings with parental investment, separately for mothers and fathers. In these analyses variables were entered in two steps: child age was entered on the first step as a control variable given the age range of the children involved, and olfactory recognition scores and hedonistic ratings were entered on the second step. Results from the second step are presented in Table 2.

Two significant findings for parents emerged. First, for fathers' emotional closeness to their children the model accounted for $13 \%$ of the variance, with olfactory recognition accuracy a significant positive predictor. Fathers who were more accurate had higher levels of emotional closeness to their children than fathers who were less accurate in recognizing their children. Second, for mothers both olfactory recognition and pleasantness ratings were predictive of physical punishment, accounting for $12 \%$ of the variance. These associations were in opposite directions. Specifically, maternal recognition accuracy showed a negative association with punishment while maternal hedonistic rating showed a positive association. That is, mothers with higher levels of olfactory recognition accuracy reported using less physical punishment with their children whereas mothers who rated their children's odors as more pleasant reported using more physical punishment.

We also limited our analyses to nonsmoking parents living in smoke-free homes (Table 3), and results are quite similar to those just reported for all households. For fathers' emotional closeness to their children, the model accounted for $26 \%$ of the

Table 1 Bivariate correlations between pleasantness ratings and parental investment (all households)

\begin{tabular}{lcc}
\hline & Fathers & Mothers \\
\hline Emotional closeness & -0.218 & 0.019 \\
Physical punishment & 0.038 & $0.259^{*}$ \\
Time investment & 0.080 & 0.106 \\
Observed affection & -0.069 & -0.069 \\
Observed ignoring & -0.086 & 0.093 \\
\hline
\end{tabular}

$* p<0.05$ 
Table 2 Parental child olfactory recognition scores and pleasantness ratings as predictors of parental investment with age of child controlled (all households)

\begin{tabular}{|c|c|c|c|c|c|c|c|c|c|c|}
\hline \multirow[b]{3}{*}{ Predictors } & \multicolumn{10}{|c|}{ Parental investment } \\
\hline & \multicolumn{2}{|c|}{$\begin{array}{l}\text { Emotional } \\
\text { closeness }\end{array}$} & \multicolumn{2}{|c|}{ Punishment } & \multicolumn{2}{|l|}{ Time } & \multicolumn{2}{|c|}{ Affection } & \multicolumn{2}{|l|}{ Ignoring } \\
\hline & $\Delta R^{2}$ & $\beta$ & $\Delta R^{2}$ & $\beta$ & $\Delta R^{2}$ & $\beta$ & $\Delta R^{2}$ & $\beta$ & $\Delta R^{2}$ & $\beta$ \\
\hline Fathers & $0.13 *$ & & 0.01 & & 0.04 & & 0.01 & & $0.09 * * *$ & \\
\hline Recognition accuracy & & $0.32 *$ & & -0.07 & & -0.17 & & -0.03 & & $-0.28 *$ \\
\hline Pleasantness rating & & -0.18 & & 0.03 & & 0.10 & & 0.08 & & -0.08 \\
\hline Mothers & 0.01 & & $0.12 * *$ & & 0.01 & & 0.01 & & 0.03 & \\
\hline Recognition accuracy & & 0.08 & & $-0.22 *$ & & -0.03 & & 0.08 & & -0.15 \\
\hline Pleasantness rating & & 0.04 & & $0.28 * *$ & & 0.09 & & 0.05 & & 0.10 \\
\hline
\end{tabular}

${ }^{*} p<0.05 ; * * p<0.01 ; * * * p<0.10$

variance, with olfactory recognition accuracy a significant positive predictor. There was a trend for a negative association between hedonistic ratings and fathers' emotional closeness. That is, the more pleasant fathers rated their children's odors, the less emotionally close they reported being to them. Maternal olfaction was related to their reports of physical punishment, accounting for $19 \%$ of the variance. Specifically, as found for the whole sample, maternal hedonistic rating showed a significant positive association while maternal recognition accuracy showed a trend for a negative association with punishment.

\section{Discussion}

To our knowledge, this is the first investigation to demonstrate that olfactory kin recognition and hedonistic ratings are related to parental investment among humans. The data presented herein, although preliminary, show that children's odor signatures may serve a role in parent-progeny investment. Here we show that fathers exhibit

Table 3 Parental child olfactory recognition scores and pleasantness ratings as predictors of parental investment with age of child controlled (non-smokers in smoke-free households)

\begin{tabular}{|c|c|c|c|c|c|c|c|c|c|c|}
\hline \multirow[b]{3}{*}{ Predictors } & \multicolumn{10}{|c|}{ Parental investment } \\
\hline & \multicolumn{2}{|c|}{$\begin{array}{l}\text { Emotional } \\
\text { closeness }\end{array}$} & \multicolumn{2}{|c|}{ Punishment } & \multicolumn{2}{|l|}{ Time } & \multicolumn{2}{|c|}{ Affection } & \multicolumn{2}{|c|}{ Ignoring } \\
\hline & $\Delta R^{2}$ & $\beta$ & $\Delta R^{2}$ & $\beta$ & $\Delta R^{2}$ & $\beta$ & $\Delta R^{2}$ & $\beta$ & $\Delta R^{2}$ & $\beta$ \\
\hline Fathers & $0.26^{*}$ & & 0.10 & & 0.02 & & 0.05 & & 0.14 & \\
\hline Recognition accuracy & & $0.42 *$ & & -0.22 & & 0.01 & & 0.16 & & $-0.38^{*}$ \\
\hline Pleasantness rating & & $-0.33 * * *$ & & 0.26 & & 0.15 & & -0.18 & & -0.06 \\
\hline Mothers & 0.01 & & $0.19 * *$ & & 0.06 & & 0.05 & & 0.04 & \\
\hline Recognition accuracy & & 0.07 & & $-0.27 * * *$ & & -0.12 & & -0.23 & & -0.21 \\
\hline Pleasantness rating & & 0.05 & & $0.41 * *$ & & 0.24 & & 0.04 & & 0.07 \\
\hline
\end{tabular}

$* p<0.05 ; * * p<0.01 ; * * * p<0.10$ 
more affection and attachment and less ignoring behaviors toward their children whose smell they can identify than toward those whose smell they cannot recognize. We found no reliable link between fathers' hedonistic ratings of their children's odors and investment.

For mothers, both olfactory recognition and hedonistic ratings of their children's odors were linked to use of physical punishment. Mothers reported using higher levels of physical punishment with children whose odors they were not able to identify and independently also reported using high levels of physical punishment with children whose odors they found pleasant. The hedonistic values mothers (and fathers) assigned to odors did not vary in the same way across recognized and unrecognized offspring. Thus, recognition of and attraction to specific odors appear to be independent mechanisms. Results from the regression analyses suggest that children with attractive odors tend to repel parents (mothers may become more hostile toward their children, while fathers are less emotionally close), whereas recognizing one's kin is associated with increases in emotional investment.

Given that the most reliable links between investment and olfactory recognition were found for fathers, we propose that olfaction may be an indirect means by which fathers assess their genetic link to offspring, which, in turn, affects their degree of emotional investment and attention. Thus, similar to what has been proposed for facial resemblance (Platek et al. 2004a), selection may have produced a response module in males that is specific to detecting and responding to olfactory cues in offspring that signal relatedness. Other offspring signals may be more salient for mothers (Stern 1997), particularly ones that would "turn off" maternal care, such as characteristics that signal diminished health and reproductive value.

Sensory mechanisms used to detect specific odortypes may be different from those needed to detect other olfactory signals (Johnston 1998). The methods in the present study are too general to address issues concerning what these specific mechanisms might be. Research in additional, larger samples is needed to determine whether our findings are replicable and whether similar links are found when the gender of the child is taken into account. In addition, given that the rate of extra-pair paternity ranges between $2 \%$ and $28 \%$ in industrialized societies, some of our purported fathers may not have been the biological fathers of their children. Previous research has demonstrated that stepmothers were unable to recognize their stepchildren's odors (Weisfeld et al. 2003), and if self-referent phenotype matching (Platek et al. 2001, 2004b) is used to recognize children's odortypes, this may have attenuated our accuracy results for fathers. Nevertheless, the link between investment and olfactory recognition should remain regardless of actual paternity, although fathers' certainty concerning paternity could serve a mediating role. Unfortunately we did not ask fathers about their degree of paternity certainty. Most important, however, the correlational nature of our study makes the direction of the effect unclear: investment may drive olfactory recognition rather than recognition driving investment. If this were true, we would also have expected a link between coresidence duration and olfactory recognition; in the present study we found no such link using age as a proxy for length of coresidence.

Well-controlled experimental studies are needed that can tease apart direction of effects and further clarify whether olfactory kin recognition is facilitated when the child's odor represents a stronger match to the parent's own odor signature. 
Experimental research might examine hypothetical investment decisions a prospective parent may be willing to invest in a child as a function of exposure to odortypes that reflect the parent, his/her mate, or a combination of the two partners. Moreover, longitudinal studies that follow parents across the transition to parenthood may shed more light on how much exposure to the child is needed to develop odor recognition and whether this ability is linked with degree of investment. Schaal and Marlier (1998) found that $80 \%$ of mothers and $92 \%$ of fathers were able to identify their newborns' amniotic fluid from that of a stranger within the first 5 days postpartum. Although based on one trial for only 15 mothers and 12 fathers, the results nevertheless suggest that relatively little exposure is needed for parents to recognize individual odor signatures, which likely represent a combination of maternal and fetal odortypes (Beauchamp et al. 1995). Olfactory cues present during pregnancy and especially at birth may be one possible trigger for the changes in testosterone levels observed among fathers with younger children (Gray et al. 2004; Storey et al. 2000; Wynne-Edwards and Reburn 2000).

Even though the mechanisms that underpin olfactory recognition remain uncertain (Johnston 1998), the preliminary findings reported herein underscore the fact that the role of olfaction in understanding individual differences in human behavior should not be ignored. Olfaction may not only be important for human sexual behaviors, it may also play a role in human parenting behaviors, especially with respect to paternal nepotism.

Acknowledgments We thank Els van Wely, Twinga van Tran, Sharon Fast, Ferieke de Heer, Fleur Hendrickx, Irene van Zuijdam, and Sophie Conijn for assistance with data collection and coding, and Paul van Noord for comments on this manuscript. This research was partially funded by the Faculty of Social Sciences, Utrecht University and by a grant to the first author by the Netherlands Organization for Scientific Research

Open Access This article is distributed under the terms of the Creative Commons Attribution Noncommercial License which permits any noncommercial use, distribution, and reproduction in any medium, provided the original author(s) and source are credited.

\section{References}

Apicella, C. L., \& Marlowe, F. W. (2004). Perceived mate fidelity and paternal resemblance predict men's investment in children. Evolution and Human Behavior, 25, 371-378.

Beauchamp, G. K., Katahira, K., Yamazaki, K., Mennella, J. A., Bard, J., \& Boyse, E. A. (1995). Evidence suggesting that the odortypes of pregnant women are a compound of maternal and fetal odortypes. Proceedings of the National Academy of Sciences, 92, 2617-2621.

Caruso, S., Grillo, C., Agnello, C., Maiolino, L., Intelisano, G., \& Serra, A. (2001). A prospective study evidencing rhinomanometric and olfactometric outcomes in women taking oral contraceptives. Human Reproduction, 16, 2288-2294.

de Brock, A. J. L. L., Vermulst, A. A., Gerris, J. R. M., \& Abidin, R. R. (1992). Nijmeegse Ouderlijke Stress Index NOSI [Nijmegen Parenting Stress Index]. Amsterdam/Lisse: Swets and Zeitlinger.

Dubas, J. S., \& Gerris, J. R. M. (2002). Longitudinal changes in the time parents spend in activities with their adolescent children as a function of child age, pubertal status and gender. Journal of Family Psychology, 16, 415-427.

Eggert, F., Muller-Ruchholtz, W., \& Ferstl, R. (1998). Olfactory cues associated with the major histocompatibility complex. Genetica, 104, 191-197. 
Gerris, J. R. M., Vermulst, A. A., van Boxtel, D. A. A. M., Janssens, J. M. A. M., van Zutphen, R. A. H., \& Felling, A. J. A. (1993). Parenting in Dutch families. Nijmegen: Institute of Family Studies, University of Nijmegen.

Gilbert, A. N., Yamazaki, K., Beauchamp, G. K., \& Thomas, L. (1986). Olfactory discrimination of mouse strains (Mus musculus) and major histocompatibility types by humans (Homo sapiens). Journal of Comparative Psychology, 100, 262-265.

Good, K. P., Martzke, J. S., Daoud, M. A., \& Kopala, L. C. (2003). Unirhinal norms for the University of Pennsylvania Smell Identification Test. Clinical Neuropsychology, 17, 226-234.

Gray, P. B., Campbell, B. C., Marlowe, F. W., Lipson, S. F., \& Ellison, P. T. (2004). Social variables predict between-subject but not day-to-day variation in the testosterone of US men. Psychoneuroendocrinology, 29, 1153-1162.

Hamilton, W. D. (1964). The genetical evolution of social behaviour. I. Journal of Theoretical Biology, 7, $1-52$.

Jacob, S., McClintock, M. K., Zelano, B., \& Ober, C. (2002). Paternally inherited HLA alleles are associated with women's choice of male odor. Nature Genetics, 30, 175-179.

Johnston, R. E. (1998). Pheromones, the vomeronasal system, and communication. From hormonal responses to individual recognition. Annals of the New York Academy of Sciences, 855, 333-348.

Kaitz, M., Good, A., Rokem, A. M., \& Eidelman, A. I. (1987). Mothers' recognition of their newborns by olfactory cues. Developmental Psychobiology, 20, 587-591.

Mackay-Sim, A., Grant, L., Owne, C., Chant, D., \& Silburn, P. (2004). Australian norms for a quantitative olfactory function test. Journal of Clinical Neuroscience, 11, 874-879.

Mateo, J. M. (2002). Kin-recognition abilities and nepotism as a function of sociality. Proceedings of the Royal Society London, Series B, 269, 721-727.

Pagel, M. (1997). Desperately concealing father: A theory of parent-infant resemblance. Animal Behavior, 53, 973-981.

Pause, B. M., Sojka, B., Krauel, K., Fehm-Wolfsdorf, G., \& Ferstl, R. (1996). Olfactory information processing during the course of the menstrual cycle. Biological Psychology, 44, 31-54.

Penn, D. J., \& Potts, W. K. (1998). Chemical signals and parasite-mediated sexual selection. Trends in Ecology and Evolution, 13, 391-396.

Platek, S. M., Burch, R. L., \& Gallup, G. G. (2001). Sex differences in olfactory self-recognition. Physiology and Behavior, 73, 635-640.

Platek, S. M., Raines, D. M., Gallup, G. G., Mohamed, F. B., Thomson, J. W., Myers, T. E., et al. (2004a). Reactions to children's faces: Males are more affected by resemblance than females are, and so are their brains. Evolution and Human Behavior, 25, 394- 405.

Platek, S. M., Thomson, J. W., \& Gallup, G. G. (2004b). Cross-modal self-recognition: The role of visual, auditory and olfactory primes. Consciousness and Cognition, 13, 197-210.

Porter, R. H. (1998). Olfaction and human kin recognition. Genetica, 104, 259-263.

Porter, R. H., \& Moore, J. D. (1981). Human kin recognition by olfactory cues. Physiology and Behavior, 27, 493-495.

Porter, R. H., Balogh, R. D., Cernoch, J. M., \& Franchi, C. (1986). Recognition of kin through characteristic body odors. Chemical Senses, 11, 389-395.

Porter, R. H., Cernoch, J. M., \& Perry, S. (1983a). The importance of odors in mother-infant interactions. Maternal Child Nursing Journal, 12, 147-154.

Porter, R. H., Cernoch, J. M., \& McLaughlin, F. J. (1983b). Maternal recognition of neonates through olfactory cues. Physiology Behavior, 30, 151-154.

Potts, W. K., Manning, C. J., \& Wakeland, E. K. (1994). The role of infectious disease, inbreeding and mating preferences in maintaining MHC genetic diversity: An experimental test. Philosophy Trans. Royal Society London Ser. B, 346, 369-378.

Reynolds, J. D., \& Sheldon, B. C. (2003). Animal behaviour: Wise fathers. Nature, 422, 669-670.

Russell, M. J., Mendelson, T., \& Peeke, H. V. (1983). Mothers' identification of their infants' odors. Ethology and Sociobiology, 4, 29-31.

Schaal, B., \& Marlier, L. (1998). Maternal and paternal perception of individual odor signatures in human amniotic fluid-Potential role in early bonding? Biology of the Neonate, 74, 266-273.

Stern, J. M. (1997). Offspring-induced nurturance: Animal-human parallels. Developmental Psychobiology, $31,19-37$.

Storey, A. E., Walsh, C. J., Quinton, R. L., \& Wynne-Edwards, K. E. (2000). Hormonal correlates of paternal responsiveness in new and expectant fathers. Evolution and Human Behavior, 21, 79-95.

Tanner, J. M. (1978). Foetus into man. Cambridge, MA: Harvard University Press. 
Weisfeld, G. E., Czilli, T., Phillips, K. A., Gall, J. A., \& Lichtman, C. M. (2003). Possible olfaction-based mechanisms in human kin recognition and inbreeding avoidance. Journal of Experimental Child Psychology, 85, 279-295.

Wynne-Edwards, K. E., \& Reburn, C. J. (2000). Behavioral endocrinology of mammalian fatherhood. Trends in Ecology and Evolution, 15, 464-468.

Yamazaki, K., Beauchamp, G. K., Singer, A., Bard, J., \& Boyse, E. A. (1999). Odortypes: Their origin and composition. Proceedings of the National Academy of Sciences, 96, 1522-1525.

Yamazaki, K., Beauchamp, G. K., Curran, M., Bard, J., \& Boyse, E. A. (2000). Parent-progeny recognition as a function of $\mathrm{MHC}$ odortype identity. Proceedings of the National Academy of Sciences, 97, 10500-10502.

Judith Semon Dubas is associate professor of developmental psychology at Utrecht University, The Netherlands. In addition to reproductive development, her research focuses on understanding within- and between-family differences in parental investment.

Marianne Heijkoop is a Ph.D. candidate in developmental psychology at Utrecht University, The Netherlands. Her dissertation research focuses on identifying child, parent and grandparent characteristics associated with individual differences in kin investment.

Marcel A. G. van Aken is professor and chair of the department of developmental psychology at Utrecht University, The Netherlands. His research focuses on the dynamic interaction between the developing individual and the (psychosocial) environment. 